

\title{
Light elements-induced iono-covalent character in MgH2: An ab-initio approach
}

Samir F. Matar

\section{To cite this version:}

Samir F. Matar. Light elements-induced iono-covalent character in MgH2: An ab-initio approach. Computational Materials Science, 2013, 69, pp.424-427. 10.1016/j.commatsci.2012.12.015 . hal00777813

\section{HAL Id: hal-00777813 \\ https://hal.science/hal-00777813}

Submitted on 18 Jan 2013

HAL is a multi-disciplinary open access archive for the deposit and dissemination of scientific research documents, whether they are published or not. The documents may come from teaching and research institutions in France or abroad, or from public or private research centers.
L'archive ouverte pluridisciplinaire HAL, est destinée au dépôt et à la diffusion de documents scientifiques de niveau recherche, publiés ou non, émanant des établissements d'enseignement et de recherche français ou étrangers, des laboratoires publics ou privés. 
Accepted: Computational Materials Science, Elsevier (12/12/12/)

\title{
Title page:
}

\section{Light elements -induced iono-covalent character in $\mathrm{MgH}_{2}$ : an ab-initio approach.}

\author{
Samir F Matar \\ CNRS, Université de Bordeaux, ICMCB, 33600 Pessac. France \\ Email: matar@icmcb-bordeaux.cnrs.fr)
}

Abstract:

The overall large ionic character of $\mathrm{MgH}_{2}$ is reduced by inserting light elements from the first period, $B$ and $C$, using a trirutile host superstructure. Both elements are found destabilizing to the structure with largely positive cohesive energy with interstitial $B$ and slightly negative cohesive energy with interstitial $C$. This trend is also observed for low amounts of insertion down to $(B, C)_{0.167} \mathrm{MgH}_{2}$. From the Bader charge analysis the largely ionic character of hydrogen is decreased to an average $H^{0.37}$ in the neighborhood of $C$ and $H^{-0.75}$ for the other hydrogen atoms atoms (resp. $H^{-0.64}$ and $H^{-0.76}$ for $B$ insertion). This peculiar behavior should enable enhancing the kinetics of $H$ release for potential applications. 


\title{
Light elements -induced iono-covalent character in $\mathrm{MgH}_{2}$ : an ab-initio approach.
}

\author{
Samir F Matar \\ CNRS, Université de Bordeaux, ICMCB, 33600 Pessac. France \\ Email: matar@icmcb-bordeaux.cnrs.fr)
}

\begin{abstract}
:
The overall large ionic character of $\mathrm{MgH}_{2}$ is reduced by inserting light elements from the first period, $B$ and $C$, using a trirutile host superstructure. Both elements are found destabilizing to the structure with largely positive cohesive energy with interstitial $B$ and slightly negative cohesive energy with interstitial $C$. This trend is also observed for low amounts of insertion down to $(B, C)_{0.167} \mathrm{MgH}_{2}$. From the Bader charge analysis the largely ionic character of hydrogen is decreased to an average $H^{-0.37}$ in the neighborhood of $C$ and $H^{-0.75}$ for the other hydrogen atoms (resp. $H^{-0.64}$ and $H^{-0.76}$ for $B$ insertion). This peculiar behavior should enable enhancing the kinetics of $H$ release for potential applications.
\end{abstract}

Keywords: $\mathrm{MgH}_{2}$, insertion, DFT, Bader, ELF, PAW, GGA.

\section{Introduction}

Metallic magnesium is a good candidate for the hydrogen storage. It can be assigned one of the largest gravimetric densities (7.6 wt. \%) owing to its light molecular weight of $24.3 \mathrm{~g} / \mathrm{mol}$. The reaction of $\mathrm{Mg}$ with hydrogen giving $\mathrm{MgH}_{2}$ is strongly exothermic and very slow, whence the stability of the hydride resulting in a strong $\mathrm{Mg}-\mathrm{H}$ chemical bond. This makes difficult the direct use of $\mathrm{MgH}_{2}$ in devices. Introducing nickel leads to materials with reversible hydrogen adsorption ability such as in $\mathrm{Mg}_{2} \mathrm{NiH}_{4}[1,2]$. Ball milling of $\mathrm{MgH}_{2}$ with carbon nanotubes leading to composites was shown to improve hydrogen absorption/desorption kinetics [3]. Recently the hydriding of magnesium mixed with graphite by ball milling was shown by us to be enhanced with best properties obtained at $150^{\circ} \mathrm{C}$; however a major role was assigned to the solvent [4]. Neither experimental works reported on possible presence of carbon within the lattice. Nevertheless the insertion of carbon or light elements of the first period into $\mathrm{MgH}_{2}$ 
should not change much the large gravimetric density necessary for applications, while modifying the electronic structure such as the cohesive energy and the charge on hydrogen, and therefore the absorption/desorption capacity. We recently showed that the large ionic character of hydrogen in ionic hydrides is strongly reduced by selective substitutions of $\mathrm{Mg}$ by $\mathrm{Ni}[5]$.

The aim of this work is to investigate the effects of insertion of light elements such as carbon and boron into $\mathrm{MgH}_{2}$, as based on computations within the quantum theoretical density functional DFT framework $[6,7]$.

\section{Calculation methodology}

The Vienna ab initio simulation package (VASP) code [8, 9] allows geometry optimization and total energy calculations. For this we use the projector augmented wave (PAW) method [9, 10], built within the generalized gradient approximation (GGA) scheme following Perdew, Burke and Ernzerhof (PBE) [11] and accounting for the valence electrons. Test calculations with PAW-GGA potentials built with including semi-core $\mathrm{Mg}-2 p$ states led to less agreement with experiment for $\mathrm{V}\left(\mathrm{MgH}_{2}\right)=57.1 \AA^{3}$ as well as less stability $\left(\mathrm{E}_{\mathrm{TOT}}=-17.55 \mathrm{eV}\right)$ as compared to the values in Table 1 on one hand and to poor convergence of the calculations for small doping concentrations of $\mathrm{B} / \mathrm{C}$ on the other hand. Also preliminary calculations with local density approximation PAWLDA [12] led to an underestimated volume versus the experiment: $\mathrm{V}_{\mathrm{LDA}}\left(\mathrm{MgH}_{2}\right)=55.6$ $\AA^{3}$ versus $\mathrm{V}_{\mathrm{GGA}}\left(\mathrm{MgH}_{2}\right)=58.2 \AA^{3}$. The conjugate-gradient algorithm [13] was used in the computational scheme to relax the atoms. The tetrahedron method with Blöchl corrections [10] as well as a Methfessel-Paxton [14] scheme were applied for both geometry relaxation and total energy calculations. Brillouin-zone (BZ) integrals were approximated using the special k-point sampling. The optimization of the structural parameters was performed until the forces on the atoms were less than $0.02 \mathrm{eV} / \AA$ and all stress components less than $0.003 \mathrm{eV} / \AA^{3}$. The calculations are converged at an energy cut-off of $400 \mathrm{eV}$ for the plane-wave basis set with respect to the k-point integration with a starting mesh of $4 \times 4 \times 4$ up to $8 \times 8 \times 8$ for best convergence and relaxation to zero strains. From the calculations, illustration for the electron localization is accessed from the ELF function introduced by Becke and Edgecombe [15] obtained from real space calculations: $\operatorname{ELF}=\left(1+\chi_{\sigma^{2}}\right)^{-1}$ with $0 \leq \mathrm{ELF} \leq 1$, i.e. it is a normalized function between 0 
(zero localization) and 1 (strong localization) with the value of $1 / 2$ corresponding to a free electron gas behavior. In this expression the ratio $\chi_{\sigma}=D_{\sigma} / D_{\sigma}{ }^{\circ}$ where $D_{\sigma}=\tau_{\sigma}-\nabla s-1 / 4$ $\left(\nabla \rho_{\sigma}\right)^{2} / \rho_{\sigma}$ and $D_{\sigma}=3 / 5\left(6 \pi^{2}\right)^{2 / 3} \rho_{\sigma}^{5 / 3}$ correspond respectively to a measure of Pauli repulsion $\left(D_{\sigma}\right)$ of the actual system and to is the free electron gas repulsion $\left(D_{\sigma}{ }^{\circ}\right)$ and $\tau_{\sigma}$ is the kinetic energy density. ELF are plotted using a small program "vaspview.exe" operating on Linux or windows, freely available from the web.

Also an analysis of the charge density is done with the approach of "atoms in molecules and crystals" (AIM) introduced by Bader [16] who developed an intuitive way of dividing molecules into atoms as based purely on the electronic charge density. For each atom in the compound, Bader considers it as surrounded by a surface running through minima of the charge density. Then the total charge of an atom is determined by integration within the Bader region. Such an analysis can be useful when trends between similar compounds are examined; they do not constitute a tool for evaluating absolute ionizations. This is the case of the presently studied compounds where we evaluate the changes in total charge on $\mathrm{H}$ comparatively.

\section{Calculations and results}

\section{1- Crystal structure and geometry optimizations.}

For the insertion of carbon and boron, the trirutile structure is a good choice as a host superstructure of $\mathrm{MgH}_{2}$. It has the same tetragonal symmetry as simple rutile with $P 4_{2} / m n m$ space group with six formula units (fu) per cell (Table 1, first two columns), on

one hand, and on the other hand the insertion can be done selectively to affect one of the three $\mathrm{Mg}$ sites, namely $\mathrm{Mg} 1$ and its neighboring $\mathrm{H} 1$ whereas $\mathrm{Mg} 2$ and its neighboring $\mathrm{H} 2$ are less subjected to direct effects of carbon or boron as shown in Fig. 1. These effects will be made explicit from the charge densities and the ELF plots in following sections.

The rutile structure presents several interstitial sites and the diffusion of foreign chemical species such as lithium within rutile was studied by Kingsbury et al. who considered based on calculations with semi-empirical Born-Mayer potentials, that beside $(8 i)$, the 
(4c) and (4d) positions as most favored energetically with little energy difference between them [17]. In present studies we considered the $(4 c)$ site for inserting carbon or boron.

\section{2- Geometry optimization and cohesive energies}

Test calculations on the $\mathrm{MgH}_{2}$ and $\mathrm{Mg}_{3} \mathrm{H}_{6}$ structures were firstly carried out. The results are shown in Table 1 at first two columns. $\mathrm{V}\left(\mathrm{MgH}_{2}\right)=58.20 \AA^{3}$ for $\mathrm{Z}=2 \mathrm{FU}$ (formula units) is smaller by $\sim 5 \%$ than experimental value of $61.62 \AA^{3}$ and very close to the volume of $\mathrm{Mg}_{3} \mathrm{H}_{6}$ trirutile $(\mathrm{Z}=2 \mathrm{FU})$ of $175.08 \AA^{3}\left(3 \times .58 .2=174.6 \AA^{3}\right)$. This also stands for the total energies. Then it becomes important to check the cohesive energy of $\mathrm{MgH}_{2}$ per $\mathrm{H}_{2}$ pair, as well as in $\mathrm{Mg}_{3} \mathrm{H}_{6}$, with respect to the experimental investigations which give $\mathrm{E}_{\text {coh. }}=-0.79 \mathrm{eV}$ following Yamagushi works [18]. For this purpose the energies of the constituents were calculated: $\mathrm{Mg}$ (hexagonal) $=-3.08 \mathrm{eV}(2 \mathrm{FU}) ; \mathrm{H} 2$ (in a large box $)=-6.52 \mathrm{eV} ; \mathrm{C}$ (hexagonal $)=-9.51 \mathrm{eV}(2 \mathrm{FU}) ; \mathrm{B}$ (tetragonal) $=-4.96$ $\mathrm{eV} / \mathrm{FU}$.

The cohesive energies per $\mathrm{H}_{2}$ pair are then obtained with $\mathrm{E}_{\text {coh. }}\left(\mathrm{MgH}_{2}\right)=-0.73 \mathrm{eV}$ and $\mathrm{E}_{\text {coh. }}\left(\mathrm{Mg}_{3} \mathrm{H}_{6}\right)=-0.75 \mathrm{eV}$. There is a closer magnitude with experiment [18] from the trirutile model than plain rutile, but the results validate the use of trirutile as a host structure for selective insertions.

Inserting the light element $(\mathrm{C}, \mathrm{B})$ is operated at $(4 c)$ Wyckoff position. Other positions such as $(2 b)$ led to unrealistic C...H neighboring with a too short distance of $\sim 1.06 \AA$. C$\mathrm{H}$ bonding would then prevail. The geometry optimizations lead to an increase of the cell volume as expected from the inserted foreign elements. The coordinates of the atomic positions are also changed leading to different $\mathrm{Mg} 1-\mathrm{H} 1$ and $\mathrm{Mg} 2-\mathrm{H} 2$ distances. Nevertheless the full geometry relaxation keeps the tetragonal structure within the $\mathrm{P}_{2} / \mathrm{mnm}$ space group. The cohesive energies are largely changed with respect to $\mathrm{MgH}_{2}$ (and $\mathrm{Mg}_{3} \mathrm{H}_{6}$ ) leading to less stable $\mathrm{C}: \mathrm{Mg}_{3} \mathrm{H}_{6}$ with $\mathrm{E}_{\text {coh. }}=-0.16 \mathrm{eV}$ and unstable B: $\mathrm{Mg}_{3} \mathrm{H}_{6}$ with a largely positive $\mathrm{E}_{\mathrm{coh}}=1.13 \mathrm{eV}$. Then it becomes relevant to investigate the changes brought by reducing the amount of inserted atoms on the cohesive energy in as far as the full occupation of $(4 c)$ positions leads to a high doping amount: $\mathrm{C}_{0.667} \mathrm{MgH}_{2}$ $\left(\mathrm{C}_{4} \mathrm{Mg}_{6} \mathrm{H}_{12}\right)$ and $\mathrm{B}_{0.667} \mathrm{MgH}_{2}\left(\mathrm{~B}_{4} \mathrm{Mg}_{6} \mathrm{H}_{12}\right)$. 
The calculations with one out of the 4 inserted $\mathrm{B} / \mathrm{C}$ atoms lead to a lowering of the tetragonal symmetry to simple monoclinic but the resulting energies allow a new evaluation of the insertion effects at very small amounts: $E_{\text {coh. }}\left(\mathrm{C}_{0.167} \mathrm{MgH}_{2}\right)=-0.41 \mathrm{eV}$ and $\mathrm{E}_{\mathrm{coh} .}\left(\mathrm{B}_{0.167} \mathrm{MgH}_{2}\right)=-0.11 \mathrm{eV}$. These values show the same trend as for large insertion amounts of stronger destabilization by boron versus carbon but both cohesive energies are now negative. It is interesting to show that the insertion of a small amount of carbon cuts the cohesive energy of $\mathrm{MgH}_{2}$ by half its magnitude.

\section{3- Assessing the changes of the iono-covalent character}

These results can be further assessed and illustrated using a charge analysis within Bader atom in molecule AIM theory [16]. Bader's analysis is done using a fast algorithm operating on a charge density grid. The program [19] reads in charge densities and outputs the total charge associated with each atom. The CHGCAR density file is obtained with high precision calculations within VASP with the conditions described in Section 2. The large ionic character of $\mathrm{MgH}_{2}$ is confirmed from calculations leading to a scattering of charge values on hydrogen according to the method and approximations in use. Using semi-core states in the PAW construction in test calculations we actually get a charge of -0.83 also obtained by [20] in studying $\mathrm{MgH}_{2}$ nano-wires, while potentials with valence electrons lead to higher ionic character with a total charge on hydrogen close to $\sim-0.97$ as shown in Table 1 for both $\mathrm{MgH}_{2}$ and $\mathrm{Mg}_{3} \mathrm{H}_{6}$. Upon the insertion of carbon there are significant deviations from the ionic character especially for $\mathrm{H} 1$ in the same plane as $\mathrm{Mg} 1$ and $\mathrm{C}$ within a range of total charges $\{-0.37$ to -0.35$\}$. This is less pronounced for $\mathrm{H} 2$ which is in the neighborhood of $\mathrm{Mg} 2$ and far from carbon. The same trends are observed with less magnitude with boron. Then the inserted element acts on hydrogen not only in its vicinity but also within the whole hydride. Experimentally an average effect should be obtained if such inserted compounds could be prepared. The difference of behavior between boron and carbon is likely due to their respective electronegativity values: $\chi(B)=2.04$ and $\chi(C)=2.55$. The less electronegative boron is less

charged than the more electronegative carbon: $\mathrm{C}^{-1.1}$ versus $\mathrm{B}^{-0.75}$, and consequently there is less charge transfer from hydrogen on it. The emerging mechanism is that the inserted element acts as a drain (or scavenger) of electrons with a magnitude proportional to its electronegativity. Also in spite of a still largely ionic $\mathrm{Mg}$, the charge on $\mathrm{Mg}$ is lower than 
in $\mathrm{MgH}_{2}$ and differentiated between $\mathrm{Mg} 1$ in the close neighborhood of $\mathrm{C}(\mathrm{B})$ carrying less positive charge than $\mathrm{Mg}$ 2. Decreasing the amount of inserted $\mathrm{C}(\mathrm{B})$ leads to less covalent character brought to hydrogen. For $\mathrm{C}_{1}: \mathrm{Mg}_{6} \mathrm{H}_{12}$ the range of charges on hydrogen $\mathrm{H} 1 / \mathrm{H} 2$ becomes $\{-0.63 ;-0.97\}$; and $\{-0.78 ;-0.98\}$ in $\mathrm{B}_{1}: \mathrm{Mg}_{6} \mathrm{H}_{12}$. Then the local effect of the $\mathrm{C}(\mathrm{B})$ interstitial is made more obvious.

\section{4- Electron localization function maps and electronic density of states}

Fig. 2 shows the ELF slices at horizontal planes crossing Mg2,H2 (Fig. 2a) and Mg1,H1 (Fig. 2b) respectively. The ionic like behavior close to that of $\mathrm{MgH}_{2}$ is observed in Fig. 2a from the strong localization (red contours with $\mathrm{ELF} \sim 0.8$ ) around $\mathrm{H} 2$ while no localization (blue contours with ELF 0.1) characterizes Mg2. On the opposite the ELF slice showing Mg1,H1 plane with carbon (Fig. 2b) exhibits different character with less localization around $\mathrm{H} 1$ and larger localization around carbon. Also the blue areas of zero localization are reduced to the immediate neighborhood of $\mathrm{Mg} 1$ with the remaining intersite areas characterized by free electron gas like behavior. These green contours, already present albeit less extensively in Fig. 2a, are indicative of an overall change of the electronic structure with respect to $\mathrm{MgH}_{2}$ which is an insulator with large gap at $\mathrm{E}_{\mathrm{V}}$ top of the valence band VB as shown in Fig. 3 displaying the total electronic density of states. The dominant $\mathrm{H}$ DOS within $\mathrm{VB}$ and $\mathrm{Mg}$ above $\mathrm{E}_{\mathrm{V}}$ is not only due to the twice larger number of $\mathrm{H}$ in the structure but also to the transfer of electrons $\mathrm{Mg} \rightarrow \mathrm{H}$ leading to an ionic hydride. The valence states of the interstitial (ex. C) are shown from the calculation to be at the bottom of VB for $\mathrm{C}(s)$ and into the gap for $\mathrm{C}(p)$.

\section{Conclusion}

From ab initio calculations, chemical modification of $\mathrm{MgH}_{2}$ by inserting light elements such as carbon or boron has been shown to lead to an iono-covalent behavior of hydrogen and to destabilizing the largely cohesive ionic $\mathrm{MgH}_{2}$. This is likely to lead to improved desorption capacity. Comparatively, boron was shown to be highly destabilizing to the lattice versus carbon. This trend is kept with decreasing amounts of inserted element. This bottom-up approach should help further experimental works.

The investigations will be extended to the dynamic study of carbon diffusion into $\mathrm{MgH}_{2}$. 
One possibility for investigating the subsequent change of $\mathrm{H}$ desorption can be approached following a methodology similar to the study of the water absorption on silica surfaces using classical molecular dynamics [21]. The studies are underway.

\section{Acknowledgements.}

The author thanks Prof. M.A. Subramanian (Oregon State University, USA) for helpful discussions during SPSSM4 conference. Exchange on the topic of the role played by carbon with Prof. M. Nakhl (Lebanese University, Lebanon) and with Dr A. Marbeuf on molecular dynamics, are also acknowledged.

Part of the calculations was carried out using the University of Bordeaux MCIA Mesocenter facilities.

\section{References:}

[1] J.J. Reilly, R.H. Wiswall Jr., Inorg. Chem. 7 (1968) 2254

[2] W.R. Myers, L-W. Wang, T. J. Richardson, M. D. Rubin, J. Appl. Phys. 91 (2002) 15 .

[3] C.Z. Wu, P. Wang, X. Yao, C. Liu, D.M. Chen, G.Q. Lu, H.M. Cheng, J. Alloys Comp. 420 (2006) 278.

[4] M. Nakhl, M. Zakhour, Ch. Amine, H. El-Rassy, S.F. Matar. Advanced Materials Research, 324 (2011) 119.

[5] A.F. Alam, S.F. Matar, N. Ouaini, Chem. Phys. Lett., 516 (2011) 174.

[6] P. Hohenberg, W. Kohn, Phys. Rev. B 136 (1964) 864.

[7] W. Kohn, L.J. Sham, Phys. Rev. A 140 (1965) 1133

[8] G. Kresse, J. Furthmüller, Phys. Rev. B 54 (1996) 11169.

[9] G. Kresse, J. Joubert, Phys. Rev. B 59 (1999) 1758.

[10] P. E. Blöchl, Phys. Rev. B 50 (1994) 17953.

[11] J. Perdew, K. Burke, M. Ernzerhof, Phys. Rev. Lett. 77 (1996) 3865.

[12] D. M. Ceperley, B. J. Alder, Phys. Rev. Lett. 45 (1980) 566.

[13] W.H. Press, B.P. Flannery, S.A. Teukolsky, W.T. Vetterling, Numerical Recipes, Cambridge University Press, New York (1986).

[14] M. Methfessel, A. T. Paxton, Phys. Rev. B 40 (1989) 3616. 
[15] A. D. Becke, K. E. Edgecombe, J. Chem. Phys. 92 (1990) 5397, and Nature 371 (1994) 683.

[16] R. Bader, Chem. Rev. 91 (1991) 893.

[17] P.I. Kingsbury Jr, W.D. Ohlsen, O.W. Johnson, Phys. Rev. 175 (1968) 1099.

[18] M. Yamaguchi, E. Akiba, in Materials Science and Technology, Cahn, Haasen and Kramers Eds. VCH, N.Y., 1994 3B, p.333.

[19] Web references for VASP and Bader charge analysis:

http://cms.mpi.univie.ac.at/vasp/vasp/Contents.html,

http://theory.cm.utexas.edu/vtsttools/bader/vasp.php, and

http://theory.cm.utexas.edu/bader/

[20] P. Vajeeston, P. Ravindran, H Fjellvåg, Nanotechnology 19 (2008) 275704.

[21] P. Bordat, P. Cazade, I. Baraille, R. Brown, J. Chem. Phys. 132 (2010), 094501.

[22] F.H. Ellinger, C.R. Holley Jr., B. McInteer, D. Pavone, R.M. Potter, E.

Staritzsky, H. Zachariasen, J. Am. Chem. Soc. 77 (1955) 2647 
Table 1: Geometry optimized lattice parameters and energies for $\mathrm{MgH}_{2}$ and C-inserted trirutile $\mathrm{Mg}_{3} \mathrm{H}_{6}$; space group $P 4_{2} / m n m . \mathrm{Mg} / \mathrm{Mg} 1(2 a$ at 000$)$ and $\mathrm{C} / \mathrm{B}\left(4 c: 01 \frac{1}{2} 0 ; 1 \frac{1}{2} 0^{1 / 2}\right.$; $\left.1 / 200 ; 01 \frac{1}{2} \frac{1}{2}\right)$ remain unchanged. Experimental values for $\mathrm{MgH}_{2}[22]$ are in italics.

\begin{tabular}{|c|c|c|c|c|}
\hline Hydride & $\mathrm{MgH}_{2}$ & $\mathrm{Mg}_{3} \mathrm{H}_{6}$ & C: $\mathrm{Mg}_{3} \mathrm{H}_{6}$ & $\mathrm{~B}: \mathrm{Mg}_{3} \mathrm{H}_{6}$ \\
\hline a / $\AA$ & $\begin{array}{l}4.418 \\
4.516 \\
\end{array}$ & 4.496 & 4.228 & 4.529 \\
\hline $\mathrm{c} / \mathrm{a}$ & $\begin{array}{l}0.675 \\
0.669\end{array}$ & 2.002 & 2.615 & 2.189 \\
\hline \begin{tabular}{|l}
$\mathrm{Mg} 1$ \\
$\mathrm{Mg} 2$ \\
$\mathrm{H} 1$ \\
$\mathrm{H} 2$
\end{tabular} & 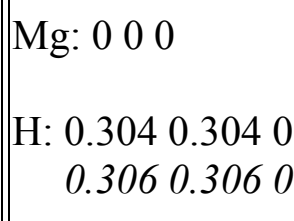 &  & 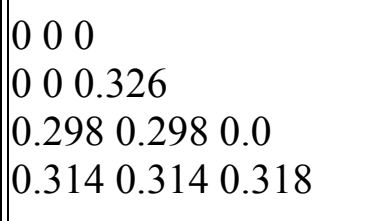 & $\mid \begin{array}{lllll}0 & 0 & 0 & \\
0 & 0 & 0.328 & \\
0.291 & 0.291 & 0.0 \\
0.310 & 0.310 & 0.320\end{array}$ \\
\hline $\begin{array}{l}\text { Shortest } \\
\text { distances/A } \\
\text { d(Mg-H) } \\
\text { d(Mg1-C/B) }\end{array}$ & $1.90 / 1.93$ & $\mid 1.94 / 1.95$ & \begin{tabular}{|l}
$1.78(\mathrm{Mg} 1-\mathrm{H} 1)$ \\
$1.88 / 1.94(\mathrm{Mg} 2-\mathrm{H} 2)$ \\
2.11
\end{tabular} & $\begin{array}{l}1.87(\mathrm{Mg} 1-\mathrm{H} 1) \\
1.96 / 2.10(\mathrm{Mg} 2-\mathrm{H} 2) \\
2.26\end{array}$ \\
\hline $\mathrm{V} / \AA^{3}$ & $\begin{array}{l}58.20 \\
61.62\end{array}$ & 175.08 & 195.88 & 205.19 \\
\hline Energy /eV & -17.57 & -52.84 & -68.307 & -61.44 \\
\hline $\mathrm{E}_{\mathrm{coh} .} / \mathrm{H}_{2} \mathrm{eV}$ & -0.73 & -0.75 & -0.16 & +1.13 \\
\hline \begin{tabular}{|l} 
Exp. \\
Exind. $/ \mathrm{H}_{2}$ \\
\end{tabular} & $\begin{array}{l}\mathrm{E}_{\text {coh. }}=-0.79 \mathrm{eV} \\
{[17]}\end{array}$ & & & \\
\hline $\begin{array}{l}\text { Bader Total } \\
\text { Charge }\end{array}$ & $\begin{array}{l}\mathrm{Mg}:+1.94 \\
\mathrm{H}:-0.99 \\
\mathrm{H}:-0.95\end{array}$ & \begin{tabular}{||l}
$<\mathrm{Mg}>+1.94$ \\
$<\mathrm{H} 1>-0.98$ \\
$<\mathrm{H} 2>-0.95$
\end{tabular} & $\begin{array}{l}\text { Mg1: }+1.92 \\
M g 2:+1.94 \\
H 1:-0.37 /-0.35 \\
H 2:-0.73 /-0.76 \\
C:-1.09\end{array}$ & $\begin{array}{l}\text { Mg1: }+1.91 \\
\operatorname{Mg} 2:+1.95 \\
H 1:-0.64 /-0.66 \\
H 2:-0.75 /-0.78 \\
B:-0.75\end{array}$ \\
\hline
\end{tabular}




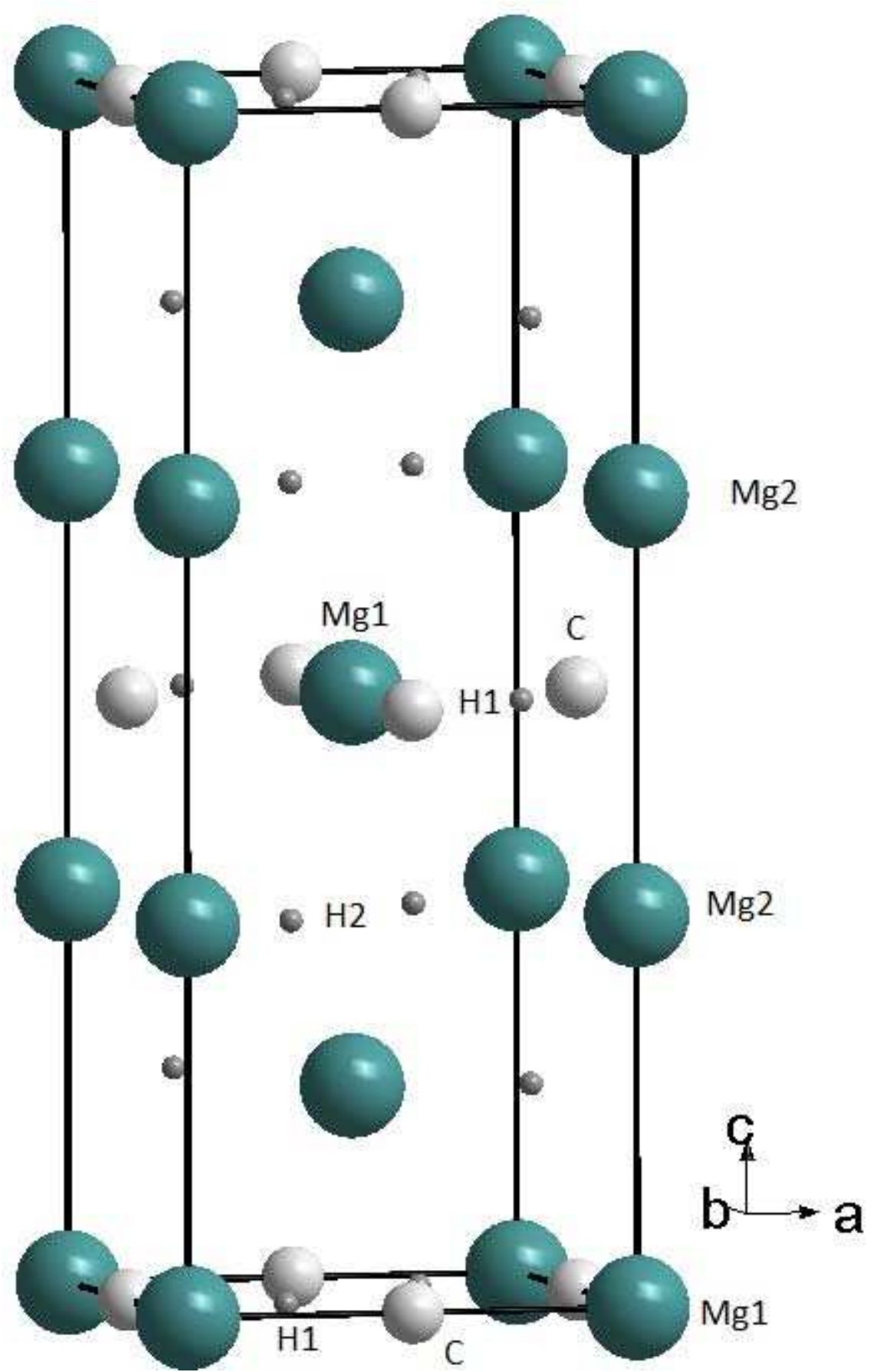

Fig.1: Sketch of the trirutile structure chosen to model light elements insertion (here $\mathrm{C}$ ) into $\mathrm{MgH}_{2}$. 


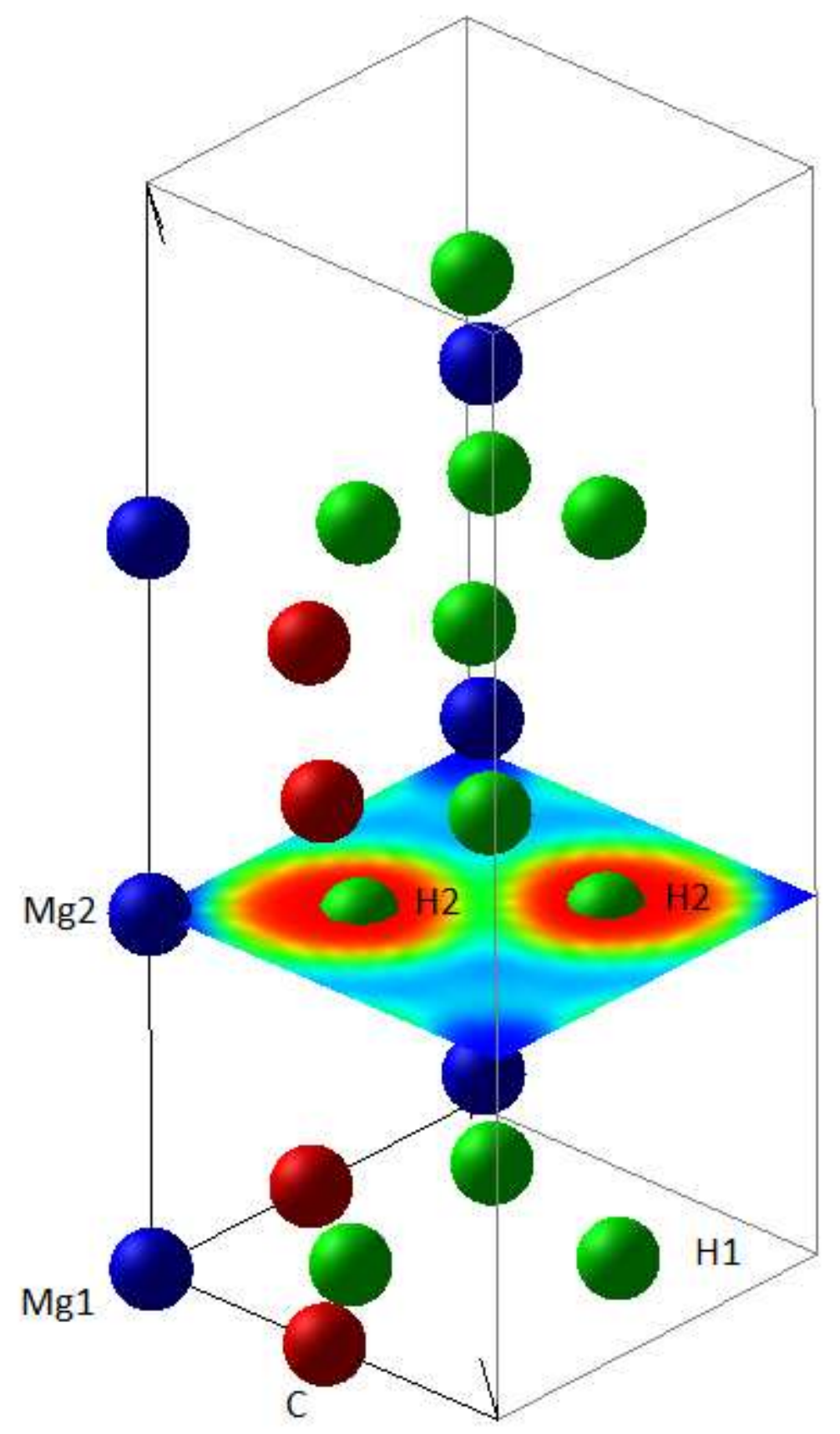

a) 


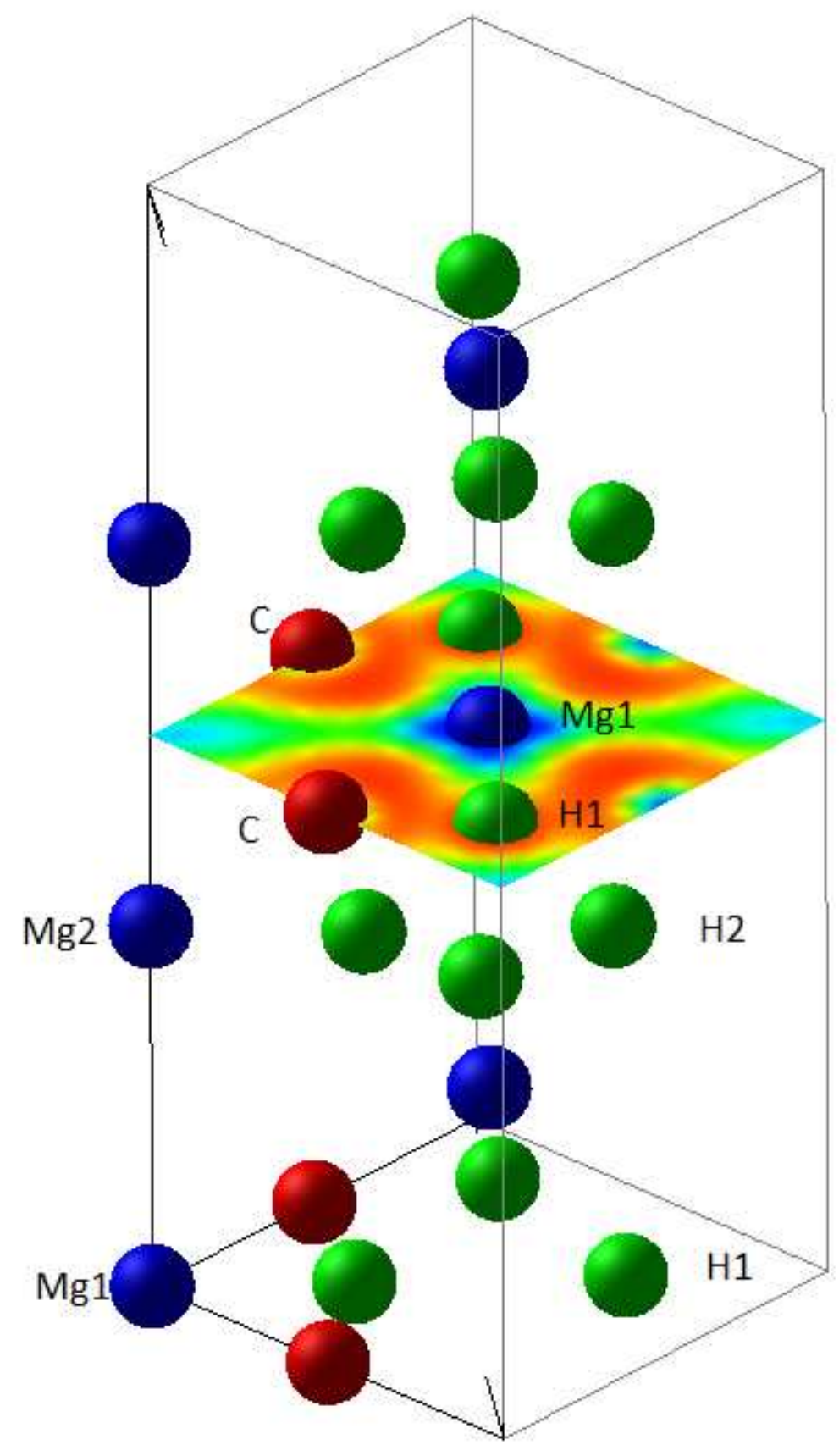

b)

Fig.2: Trirutile $\mathrm{MgH}_{2}$ : Electron localization function ELF slices perpendicular to the $c$ axis showing planes at a) $\mathrm{Mg} 2, \mathrm{H} 2$ and b) at $\mathrm{Mg} 1, \mathrm{H} 1$ with carbon. 


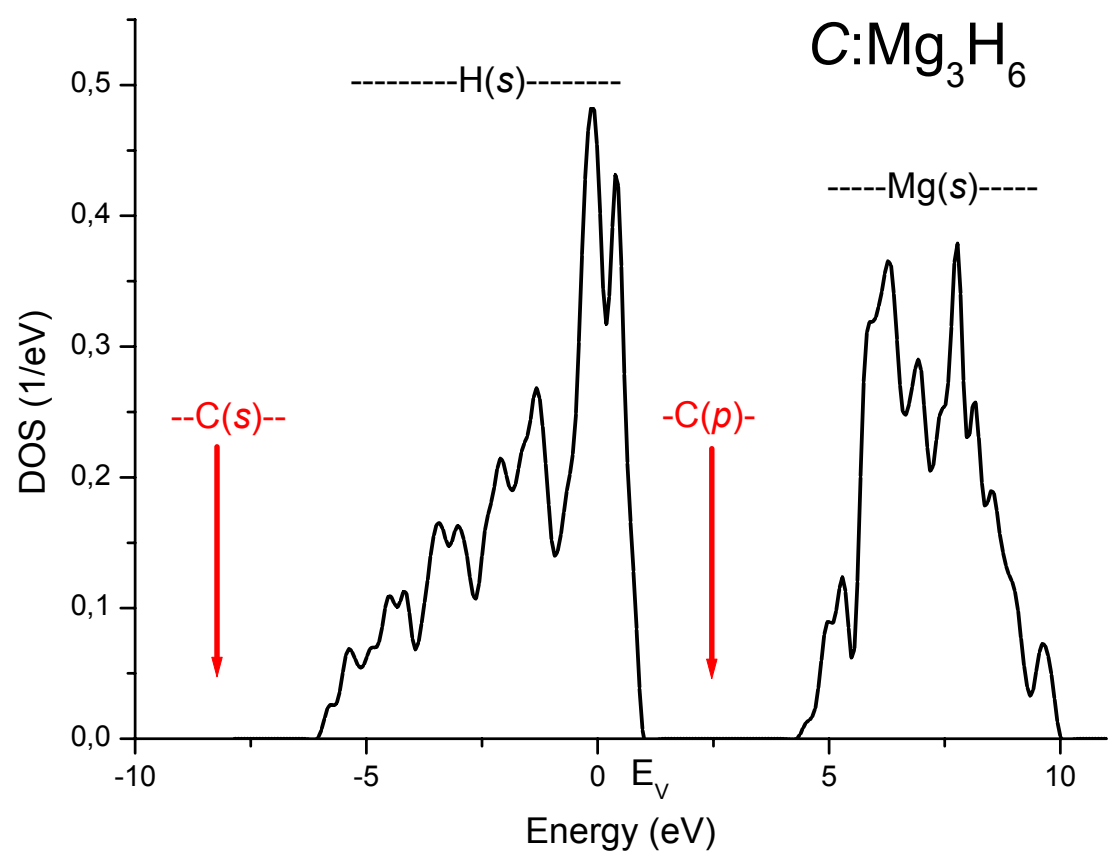

Fig.3: Total electronic density of states for trirutile $\mathrm{MgH}_{2}$ with the relative positions of carbon valence states for carbon inserted hydride. 